\title{
Article
}

\section{Influence of minimalist footwear on knee and ankle loads during the squash lunge}

Sinclair, Jonathan Kenneth, Bottoms, Lindsay, Taylor, Paul John and Mahmood, Khizar

Available at http://clok.uclan.ac.uk/12474/

Sinclair, Jonathan Kenneth ORCID: 0000-0002-2231-3732, Bottoms, Lindsay, Taylor, Paul John ORCID: 0000-0002-9999-8397 and Mahmood, Khizar (2015) Influence of minimalist footwear on knee and ankle loads during the squash lunge. Movement and Sport Sciences. ISSN 2118-5735

It is advisable to refer to the publisher's version if you intend to cite from the work. http://dx.doi.org/10.1051/sm/2015025

For more information about UCLan's research in this area go to http://www.uclan.ac.uk/researchgroups/ and search for <name of research Group>.

For information about Research generally at UCLan please go to http://www.uclan.ac.uk/research/

All outputs in CLoK are protected by Intellectual Property Rights law, including Copyright law. Copyright, IPR and Moral Rights for the works on this site are retained by the individual authors and/or other copyright owners. Terms and conditions for use of this material are defined in the policies page.

\section{CLoK}

Central Lancashire online Knowledge www.clok.uclan.ac.uk

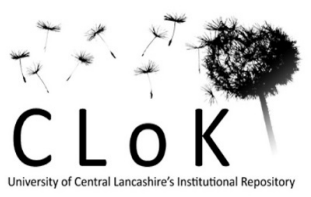




\title{
Influence of minimalist footwear on knee and ankle loads during the squash lunge
}

\author{
Jonathan Sinclair ${ }^{1}$, Lindsay Bottoms ${ }^{2}$, Paul John Taylor ${ }^{3}$ and Khizar Mahmood ${ }^{1}$ \\ 1 Centre for Applied Sport and Exercise Sciences, School of Sport Tourism and Outdoors, University of Central Lancashire, \\ Preston, United kingdom \\ 2 Department of Human and Environmental Sciences, School of Life and Medical Sciences, University of Hertfordshire, \\ United kingdom \\ ${ }^{3}$ School of Psychology, University of Central Lancashire, United kingdom
}

Received 14 May 2015 - Accepted 4 August 2015

\begin{abstract}
Squash is associated with a high incidence of knee and ankle joint injuries. The aim of this work was to examine the effects of squash specific, running shoes and minimalist footwear on knee and ankle loads during the lunge movement in squash players. Twelve male squash players performed lunge movements whilst wearing squash specific, running shoes and minimalist footwear. The loads experienced by the knee and ankle joints were calculated. Patellofemoral forces were significantly greater in running shoes $(5.10$ B.W) compared to minimalist footwear $(4.29 \mathrm{~B} . \mathrm{W})$. Achille tendon forces were significantly larger in the minimalist footwear (3.10 B.W) compared to the running shoes $(2.64$ B.W) and squash specific footwear $(2.88$ B.W $)$. This shows that whilst minimalist footwear may reduce the incidence of knee pathologies in squash players corresponding increases in ankle loading may induce an injury risk at this joint.
\end{abstract}

Key words: Biomechanics, squash, knee, ankle, footwear

Résumé. Influence de la chaussure minimaliste sur les charges du genou et de la cheville lors de la fente de squash.

La pratique du squash est associée à des lésions articulaires au niveau du genou et de la cheville. Le but de ce travail était d'examiner les effets du port de chaussures de course à pied, de chaussures spécifiques de squash et de chaussures minimalistes sur les contraintes au niveau du genou et de la cheville pendant le mouvement de fente chez des joueurs de squash. Les contraintes aux articulations du genou et de la cheville ont été calculées pour douze joueurs de squash avec les différents types de chaussures. Les forces fémoro-patellaires étaient significativement plus grandes avec les chaussures de course $(5,10 \times$ poids de corps $)$ par rapport aux chaussures minimalistes $(4,29 \times$ poids de corps $)$. Les forces au niveau du tendon d'Achille étaient significativement plus grandes avec les chaussures minimalistes $(3.10 \times$ poids de corps $)$ par rapport aux chaussures de course $(2,64 \times$ poids de corps $)$ et aux chaussures spécifiques de squash $(2,88 \times$ poids de corps). En conclusion, les chaussures minimalistes pourraient réduire les pathologies du genou chez les joueurs de squash, cependant une augmentation des contraintes au niveau du tendon d'Achille pourrait induire parallèlement un risque de blessure au niveau de l'articulation de la cheville.

Mots clés : Biomécanique, squash, genou, cheville, chaussures

\section{Introduction}

2 Squash is an extremely popular sport with millions of 3 players in over 100 countries worldwide. Competitive 4 squash is a physically demanding sport characterised by 5 a series of accelerations and decelerations which involve 6 both lunging and side-stepping (Vuckovic \& James, 2010).
The repetitive nature and intensity of squash means that squash players are at risk from injuries.

Injuries of a chronic nature are commonplace in both recreational and competitive squash players (Clavisi \& Finch, 2000), with an occurrence rate of $45 \%$ (Berson, Rolnick, Ramos, \& Thornton, 1981). Chronic musculoskeletal pathologies in squash players occur in both the 
upper and lower limbs and also the lower back (Finch \& Eime, 2001). Lower extremities injuries are most common, with the knee and ankle joints being the most commonly injured sites (Finch \& Eime, 2001).

Clavisi \& Finch (2000) proposed that inappropriate footwear is a potential contributing factor to the aetiology of lower extremity injures in squash players. Indeed Shorten (1993) suggests that through appropriate footwear design/ selection athletes may be able to regulate their susceptibility to chronic injuries. There is currently a lack of published research investigating the effects of different footwear on the biomechanical parameters linked to the aetiology of injury development in squash. There is a trend in a number of sporting disciplines for athletes to choose minimalist footwear as opposed to sport specific or running shoes (Sinclair, Atkins, Taylor, \& Vincent, 2015a), based on the supposition that running in minimalist footwear is associated with a reduced incidence of lower extremity injuries (Sinclair, Greenhalgh, A., Brooks, Edmundson, \& Hobbs, 2013a).

Research in other sports has examined the effects of minimalist footwear on the loads experienced by the knee and ankle joints. Sinclair (2014) investigated the effects of barefoot and minimalist footwear on knee and ankle loads during running compared to running shoes. Running barefoot and in minimalist footwear reduced the loads experienced by the knee but also increased the loads on the ankle compared to running shoes. Bonacci, Vicenzino, Spratford, \& Collins (2013) showed that running barefoot reduced the loads experienced by the knee compared to running in conventional running shoes. Sinclair, Chockalingam, Naemi, \& Vincent (2015b) showed that minimalist footwear reduced the loads experienced by the knee during depth jumping compared to running shoes, but there were no differences in ankle loads. Finally Sinclair, Hobbs, \& Selfe (2015c) showed that minimalist footwear reduced the load on the knee but increased the load experienced by the ankle compared to netball specific footwear. However, there is currently no research which has investigated the effects of different footwear in squash players. This indicates further study regarding the effects of different footwear on the loads experienced by the knee and ankle joints in squash specific movements is warranted.

The lunge is a movement that is used regularly in competitive squash, and the ability to quickly execute a controlled lunge is a key component of the game (Cronin, McNair, \& Marshall, 2003). The aim of the current investigation was therefore to examine the effects of squash specific, running shoes and minimalist footwear on the loads experienced by the knee and ankle during the squash lunge. An investigation of this nature may provide key information to squash players regarding selection of appropriate footwear. This study tests the hypothesis that the minimalist footwear will be associated with decreased knee loading in comparison to the squash specific and running shoes

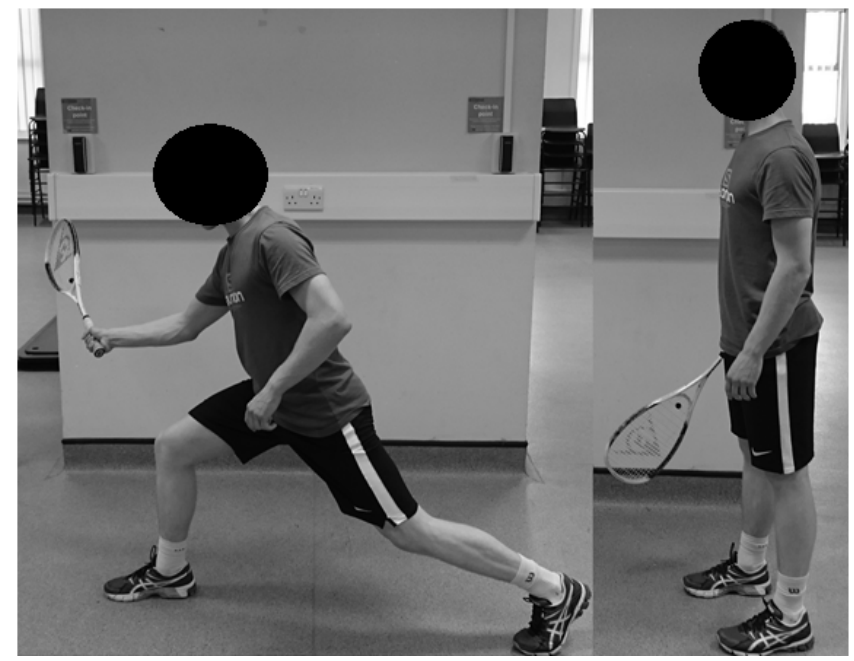

Fig. 1. Example of the squash lunge movement.

\section{Methods}

\subsection{Participants}

Twelve male participants (Age $21.59 \pm 2.28$ years; height $1.74 \pm 0.07 \mathrm{~m}$; mass $68.12 \pm 4.54 \mathrm{~kg}$ ) volunteered to take part in the current investigation. Participants were all competitive university level squash players. Ethical approval for this project was obtained from the University ethics committee, and each participant provided written consent in accordance with the declaration of Helsinki.

\subsection{Procedure}

Participants completed five lunges in each footwear condition starting from a stationary position facing forward (Fig. 1). Following each lunge they were required to return to a starting point which was determined by each participant prior to the commencement of data collection. This allowed the lunge distance to be maintained for each condition. Participants were also required to contact a force platform (Kistler, Kistler Instruments Ltd., Alton, Hampshire) embedded into the floor of the biomechanics laboratory with their right (lead) foot. The force platform sampled at $1000 \mathrm{~Hz}$. The lunge movement was considered to begin at the point of foot contact, this was taken as the point at which $>20 \mathrm{~N}$ of vertical force was applied to the force platform. The end of the lunge movement was taken as the point of maximum knee flexion (Sinclair \& Bottoms, 2013). The peak linear velocity $(\mathrm{m} / \mathrm{s})$ of the lunge movement was quantified using the centre of mass of the pelvis segment (Sinclair, Toth, \& Hobbs, 2015d).

Kinematic information was obtained using an eight camera optoelectric system capture system (Qualisys Medical AB, Goteburg, Sweden) using a capture frequency of $250 \mathrm{~Hz}$. Kinematics and force platform data were synchronized using an analogue to digital interface 
1 board. To model the lower extremity segments in six degrees of freedom the calibrated anatomical systems technique was utilized (Cappozzo, Catani, Leardini, Benedeti, \& Della, 1995). To define the segment co-ordinate axes of the right; foot, shank and thigh, retroreflective markers were placed unilaterally onto 1st metatarsal, 5th metatarsal, calcaneus, medial and lateral malleoli, medial and lateral epicondyles of the femur. To define the pelvic segment, additional markers were placed on the anterior (ASIS) and posterior (PSIS) superior iliac spines. The centres of the ankle and knee joints were delineated as the mid-point between the malleoli and femoral epicondyle markers (Graydon, Fewtrell, Atkins, \& Sinclair 2015; Sinclair Hebron, \& Taylor 2015e). The hip joint centre was delineated using a regression equation in accordance with Sinclair, Taylor, Currigan, \& Hobbs (2014a) (Fig. 2).

The $Z$ (transverse) axis was oriented vertically from the distal segment end to the proximal segment end. The $Y$ (coronal) axis was oriented in the segment from posterior to anterior. Finally, the $X$ (sagittal) axis orientation was determined using the right hand rule and was oriented from medial to lateral. Carbon fibre tracking clusters were positioned onto the shank and thigh segments. The foot was tracked using the 1st metatarsal, 5th metatarsal and calcaneus markers. Static calibration trials were obtained allowing for the anatomical markers to be referenced in relation to the tracking markers/ clusters. Previous work has confirmed that the reliability of this marker configuration is very high (Sinclair, et al., 2012).

\subsection{Data processing}

Ground reaction force (GRF) and marker data were filtered at $50 \mathrm{~Hz}$ and $12 \mathrm{~Hz}$ using a low-pass Butterworth 4th order filter and processed using Visual 3-D (C-Motion, Germantown, MD, USA). Joint kinetics were computed using Newton-Euler inverse-dynamics, allowing net knee and ankle joint moments to be calculated. To quantify joint moment's se gment mass, segment length, GRF and angular kinematics were utilized using the procedure previously described by Sinclair (2014).

Knee loading was examined through extraction of peak knee extensor/ abduction moments, peak patellofemoral contact force (PTCF) and peak patellofemoral contact pressure (PTS). PTCF during the lunge was estimated using knee flexion angle $(k f a)$ and knee extensor moment (KEM) through the biomechanical model of Ho Blanchette, and Powers (2012). This model has been utilized previously to resolve differences in PTCF and PTS in during the lunge movement and when different footwear (Bonacci, et al., 2013; Sinclair, 2014; Sinclair \& Bottoms, 2015). In addition to this previous work has confirmed the robustness of this model through sensitivity analyses for each of the measures (Sinclair, Taylor, \& Atkins, 2015f).

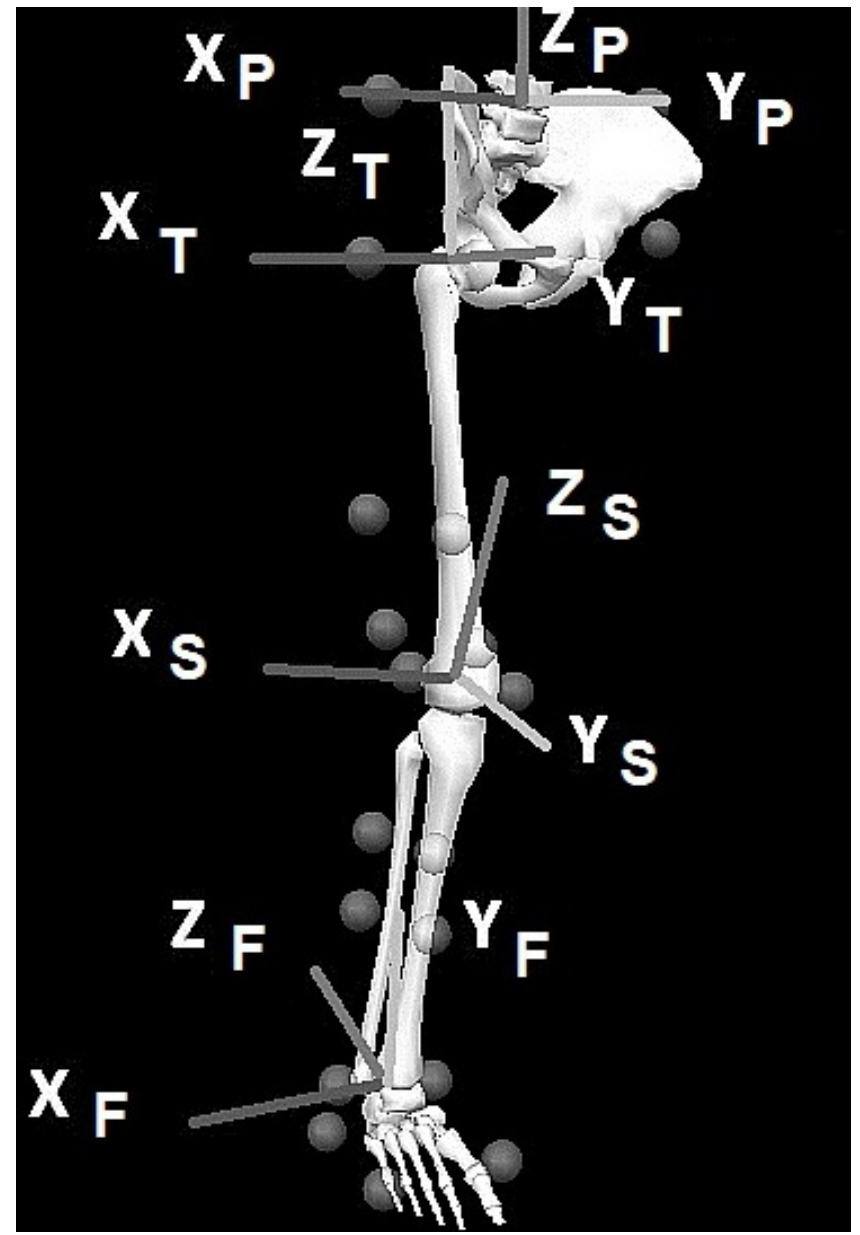

Fig. 2. Pelvic, thigh, tibial and foot segments, with anatomical axes. $\mathrm{P}=$ Pelvis, $\mathrm{S}=$ Shank, $\mathrm{T}=$ tibia and $\mathrm{F}=$ foot.

The effective moment arm distance $(\mathrm{m})$ of the quadriceps muscle (QM) was calculated as a function of $k f a$ using a non-linear equation, based on information presented by Van Eijden, Kouwenhoven, Verburg, \& Weijs (1986):

$$
\mathrm{QM}=0.00008 k f a^{3}-0.013 k f a^{2}+0.28 k f a+0.046
$$

The force $(\mathrm{N})$ of the quadriceps $(\mathrm{QF})$ was calculated using the below formula:

$$
\mathrm{QF}=\mathrm{KEM} / \mathrm{QM}
$$

Net PTCF was estimated using the QF and a constant $(C)$ :

$$
\mathrm{PTCF}=\mathrm{QF} * \mathrm{C}
$$

The $C$ was described in relation to $k f a$ using a curve fitting technique based on the non-linear equation described by Van Eijden, et al. (1986):

$$
\begin{gathered}
C=\left(0.462+0.00147 * k f a^{2}-0.0000384 * k f a^{2}\right) / \\
\left(1-0.0162 * k f a+0.000155 * k f a^{2}-0.000000698 * k f a^{3}\right)
\end{gathered}
$$


Table 1. Abbreviations of input parameters for knee and ankle load models.

\begin{tabular}{cc}
\hline Key & \\
\hline Patellofemoral contact force & PTCF \\
Patellofemoral contact pressure & PTS \\
Knee flexion angle & $k f a$ \\
Knee extensor moment & KEM \\
Quadriceps moment arm & QM \\
Quadriceps force & QF \\
Constant & C \\
Achilles tendon force & ATF \\
Ankle plantarflexor moment & MPF \\
Achilles tendon moment arm & mat \\
Sagittal ankle angle & $a k$ \\
\hline
\end{tabular}

1 PTS (MPa) was calculated using the net PTCF divided 2 by the patellofemoral contact area. The contact area was 3 described using the Ho, et al. (2012) recommendations by

4 fitting a $2^{\text {nd }}$ order polynomial curve to the data of Powers, 5 Lilley, \& Lee (1998) showing patellofemoral contact areas at varying levels of $k f a$.

$\mathrm{PTS}=\mathrm{PTCF} /$ contact area

Ankle loading was examined through extraction of the peak plantar flexion moment and peak Achilles tendon force (ATF). ATF was determined by dividing the plantarflexion moment (MPF) by the estimated Achilles tendon moment arm (mat). The moment arm was quantified as a function of the ankle sagittal plane angle $(a k)$ using the procedure described by Self \& Paine (2001):

$$
\begin{gathered}
\mathrm{ATF}=\mathrm{MPF} / \mathrm{mat} \\
\text { mat }=-0.5910+0.08297 a k-0.0002606 a k^{2}
\end{gathered}
$$

The net joint moments were normalized by dividing by body mass $(\mathrm{Nm} / \mathrm{kg})$. PTCF and ATF were also normalized by dividing by body weight (B.W). These variables were extracted from each of the five trials and the data was then averaged within participants for statistical analysis. In accordance with Sinclair, Isherwood, \& Taylor (2014b) GRF's in all three axes and sagittal knee/ ankle angles at the instances of peak PTCF and ATF were also obtained. GRF's were normalized by dividing by bodyweight.

\subsection{Experimental footwear}

The footwear used during the current investigation consisted of a running shoe (New balance $1260 \mathrm{v} 2$ ), minimalist footwear (Vibram five-fingers, ELX) and squash specific shoe (Asics Mens GEL Rocket 7 Indoor), (shoe size 8-10 UK men's). 2013b). Post-hoc pairwise comparisons were conducted on all significant main effects using a Bonferroni adjustment. Effect sizes were calculated for each significant main effect using partial eta ${ }^{2}\left(p \eta^{2}\right)$. The normality assumption was calculated using a Shapiro-Wilk test, which confirmed that all data were normally distributed. All statistical procedures were conducted using SPSS v22.0 (SPSS Inc, Chicago, USA).

\section{Results}

Figure 3 and Tables 2-3 show GRFs and knee/ ankle loads as a function of footwear. The statistical findings indicate that both knee and ankle loads were significantly influenced as a function of footwear.

\subsection{Lunge velocity}

No significant $(p>0.05)$ differences in lunge velocity were found between running shoe $(1.65 \pm 0.32 \mathrm{~m} / \mathrm{s})$, minimalist $(1.63 \pm 0.32 \mathrm{~m} / \mathrm{s})$ and squash specific footwear $(1.64 \pm$ $0.27 \mathrm{~m} / \mathrm{s})$.

\subsection{Ground reaction forces and joint angles}

No significant $(p>0.05)$ differences in GRF's at the instances of PTCF of ATF were shown between footwear. A significant main effect was shown $\left(P<0.05, p \eta^{2}=0.33\right)$ for knee flexion angle at the instance of PTCF. Post-hoc pairwise comparisons showed that knee flexion was significantly larger in the running shoes $(P=0.014)$ compared to the minimalist condition.

\subsection{Knee loads}

A significant main effect was shown $\left(P<0.05, p \eta^{2}=\right.$ 0.32 ) for peak knee extensor moment. Post-hoc pairwise comparisons showed that peak extensor moment was significantly larger in the running shoes $(P=0.04)$ compared to the minimalist condition. In addition a significant main effect was found for PTCF $(P<0.05$, $\left.p \eta^{2}=0.42\right)$. Post-hoc analysis indicated that PTCF was significantly larger in the running shoes $(P=0.03)$ compared to the minimalist condition. Finally a significant main effect was found for PTS $\left(P<0.05, p \eta^{2}=0.41\right)$. Post-hoc analysis indicated that PTS was significantly larger in the running shoes $(P=0.03)$ compared to the minimalist condition.

\subsection{Ankle loads}

A significant main effect was shown $\left(P<0.05, p \eta^{2}=\right.$ 0.46 ) for peak ankle plantarflexor moment. Post-hoc pairwise comparisons showed that peak plantarflexor moment 

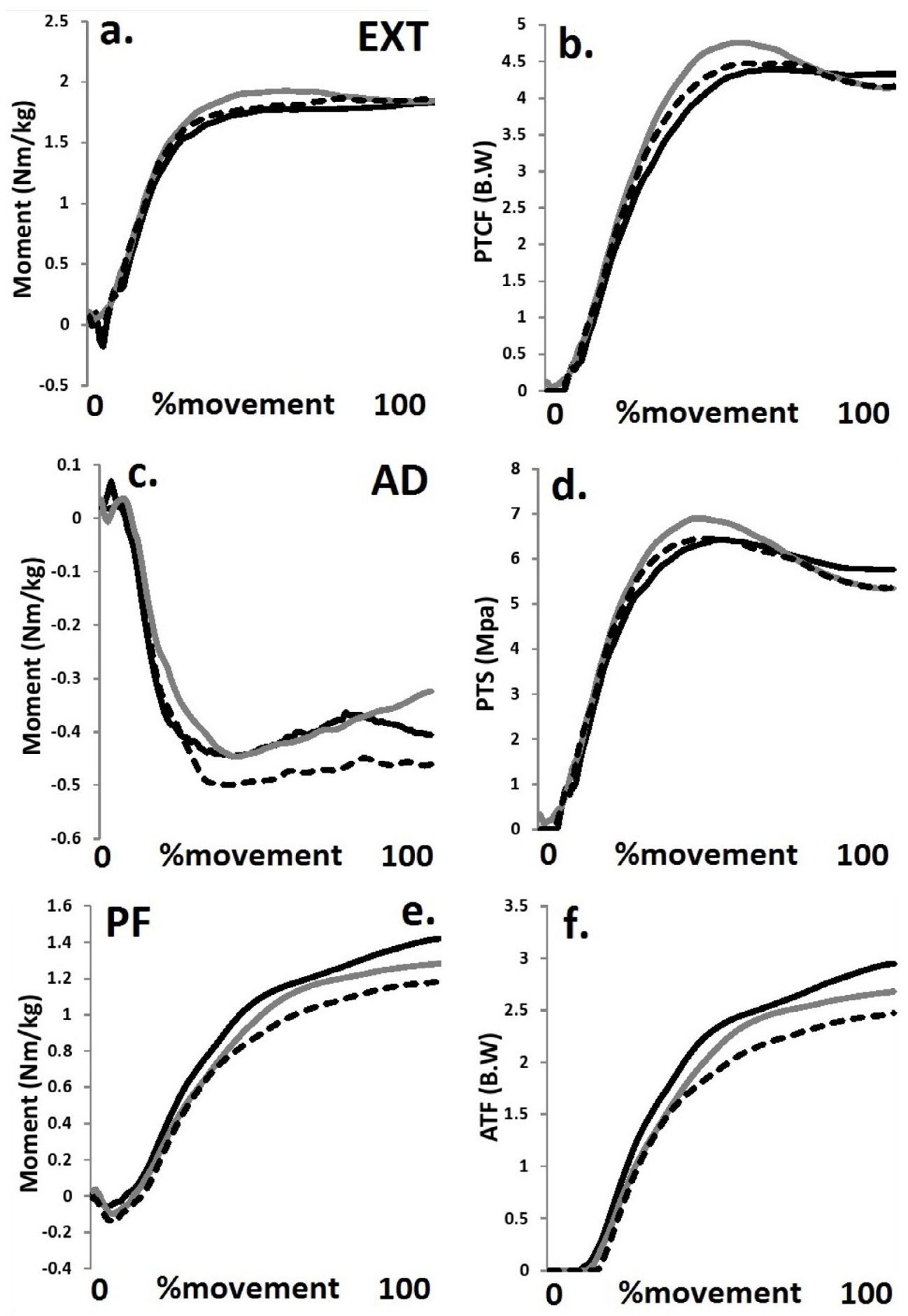

\section{Key \\ Minimalist \\ Squash specific \\ Running shoe}

Fig. 3. Knee and ankle loads as a function of footwear (a. = knee extensor moment, b. $=$ PTFC, c. $=$ knee abduction moment, d. $=$ PTS, e. $=$ plantarflexor moment, f. $=\mathrm{ATF})(\mathrm{EXT}=$ extensor, $\mathrm{AD}=$ adductor, $\mathrm{PF}=$ plantarflexor $)$. 
Table 2. GRF's and knee/ ankle angles as a function of footwear.

\begin{tabular}{|c|c|c|c|c|c|c|c|}
\hline & \multicolumn{2}{|c|}{ Running shoe } & \multicolumn{2}{|c|}{ Minimalist } & \multicolumn{3}{|c|}{ Squash footwear } \\
\hline & Mean & $S D$ & Mean & $S D$ & Mean & $S D$ & \\
\hline Medial force at PTCF (B.W) & 0.05 & 0.07 & 0.04 & 0.07 & 0.04 & 0.07 & \\
\hline Anterior force at PTCF (B.W) & 0.29 & 0.09 & 0.29 & 0.09 & 0.27 & 0.11 & \\
\hline Vertical force at PTCF (B.W) & 1.19 & 0.17 & 1.18 & 0.17 & 1.19 & 0.18 & \\
\hline Knee angle at PTCF $\left(^{\circ}\right)$ & $145.25 A$ & 36.36 & 137.07 & 35.35 & 142.85 & 37.31 & * \\
\hline Medial force at ATF (B.W) & 0.06 & 0.02 & 0.03 & 0.06 & 0.02 & 0.05 & \\
\hline Anterior force at ATF (B.W) & 0.22 & 0.10 & 0.24 & 0.10 & 0.26 & 0.09 & \\
\hline Vertical force at ATF (B.W) & 1.17 & 0.17 & 1.19 & 0.16 & 1.16 & 0.17 & \\
\hline Ankle angle at ATF $\left(^{\circ}\right)$ & 19.75 & 9.29 & 21.04 & 8.82 & 19.82 & 4.65 & \\
\hline
\end{tabular}

$*$ = significant main effect.

$A=$ significantly different from minimalist.

Table 3. Knee and ankle loads as a function of footwear.

\begin{tabular}{|c|c|c|c|c|c|c|c|}
\hline & \multicolumn{2}{|c|}{ Running shoe } & \multicolumn{2}{|c|}{ Minimalist } & \multicolumn{3}{|c|}{ Squash footwear } \\
\hline & Mean & $S D$ & Mean & $S D$ & Mean & $S D$ & \\
\hline Peak knee extensor moment $(\mathrm{Nm} / \mathrm{kg})$ & $2.16 \mathrm{~A}$ & 0.58 & 2.03 & 0.52 & 2.13 & 0.56 & * \\
\hline Peak knee abduction moment $(\mathrm{Nm} / \mathrm{kg})$ & 0.71 & 0.37 & 0.67 & 0.38 & 0.64 & 0.32 & \\
\hline Peak PTCF (B.W) & $5.10 A$ & 1.36 & 4.29 & 1.49 & 4.66 & 1.45 & * \\
\hline Peak PTS (Mpa) & $6.94 A$ & 2.10 & 5.67 & 2.38 & 6.04 & 2.24 & * \\
\hline Peak plantarflexor moment $(\mathrm{Nm} / \mathrm{kg})$ & $1.26 \mathrm{~A}$ & 0.21 & 1.49 & 0.29 & $1.38 \mathrm{~A}$ & 0.22 & * \\
\hline Peak ATF (B.W) & $2.64 A$ & 0.47 & 3.10 & 0.63 & $2.88 A$ & 0.48 & * \\
\hline
\end{tabular}

* = significant main effect.

$A=$ significantly different from minimalist.

was significantly larger in the minimalist footwear compared to the squash specific $(P=0.026)$ and running shoes $(P=0.005)$. A significant main effect was also found $\left(P<0.05, p \eta^{2}=0.40\right)$ for ATF. Post-hoc pairwise comparisons showed that ATF was significantly larger in the minimalist footwear compared to the squash specific $(P=0.029)$ and running shoes $(P=0.007)$.

\section{Discussion}

The aim of the current investigation was to examine the effects of different footwear on the loads experienced by the knee and ankle joints during the squash lunge. This represents the first investigation to study the effects of different footwear on knee and ankle loads in squash players. As the knee and ankle joints are the most frequently injured sites in squash players, this work may provide important information to squash players regarding the selection of appropriate footwear.

From these findings the first important observation is that peak knee loads were significantly larger in the running shoes in comparison to the minimalist footwear This observation concurs with previous work investigating knee loading in runners. Sinclair (2014), Bonacci, et al. (2013), Sinclair, et al. (2015b, 2015c) each showed that knee loading in runners was significantly larger in running shoes footwear compared to barefoot and in minimalist footwear. This may be attributable to the significant increase in peak knee extensor moment and decrease in knee flexion angle at PTCF. Increases in knee flexion are linked to a shortening of the quadriceps moment arm, which ultimately leads to an increase in the load borne by the patellofemoral joint (Sinclair, 2014). This finding may have clinical significance regarding the aetiology of injury in squash players as the consensus regarding the development of knee pathologies is that symptoms are the function of excessive knee joint kinetics (LaBella, 2004). Therefore it appears that for squash players susceptible to knee injuries that minimalist footwear may be more appropriate than running shoes although they do not appear to provide any advantage compared to squash footwear.

Of further importance is the finding that peak ankle loads were significantly greater in the minimalist footwear in comparison to the squash specific and running shoe conditions. This observation also concurs with the findings of Sinclair (2014) and Sinclair, et al. (2015c) who showed in runners that ankle loading was significantly larger when wearing minimalist footwear in comparison to conventional athletic trainers. It is proposed that this observation relates to the increase plantarflexion moment contribution observed in minimalist footwear as no differences in ankle angle were shown between footwear. This finding may also have relevance clinically as the development of Achilles tendon pathology is mediated by excessive and habitual loading of the tendon during dynamic activities (Magnusson, Langberg, \& Kjaer, 2010). When the load experienced exceeds levels that are tolerable by the tendon itself this causes degeneration of the 
1 tendon and eventually leads to injury (Selvanetti, Cipolla, \& Puddu, 1997). Based on this observation this study in3 dicates that for squash players who are predisposed to ankle pathologies, that squash specific and running shoes are most appropriate.

A potential drawback of the current study is that only male squash players were tested. Sinclair \& Bottoms (2014), and Sinclair \& Bottoms (2015) showed that knee loads were significantly larger in females and ankle loads were significantly greater in males during the lunge. As such it appears that the findings from this study may not be generalizable to female squash players. Future research should seek to repeat this study using a sample of female squash players. A further limitation is that only the lunge movement was investigated. The lunge was chosen as it represents a high impact movement (Sinclair, Bottoms, Taylor, \& Greenhalgh, 2010), which exposes the musculoskeletal system to high forces. Competitive squash also requires other motions for success including sprinting, pivot turning and side stepping. Therefore future research should investigate the effects of different footwear when performing different squash movements.

In conclusion, the observations of the current investigation show that performing the lunge movement in minimalist footwear produced significant reductions in knee loading compared to running shoes. Given the proposed relationship between knee loading and knee joint pathology, squash players may be able to attenuate their risk of the developing knee injuries by wearing minimalist footwear as opposed to running shoes. However, taking into account the corresponding increase in ankle loading in minimalist footwear in comparison to the running shoes and squash specific footwear, this may also enhance the likelihood of chronic ankle injuries. Additional analyses are required in order to expand the current investigation to squash specific movements in addition to the lunge.

\section{7} mance and its determinants. Journal of Sports Sciences, 21, 49-57.
Finch, C., \& Eime, R. (2001). The epidemiology of squash injuries. International Journal of Sports Medicine, 2, 1-11.

Graydon, R., Fewtrell, D., Atkins, S., \& Sinclair, J. The testretest reliability of different ankle joint center location techniques. The Foot and Ankle Online journal, 8, 1-11.

Ho, K.Y., Blanchette, M.G., \& Powers, C.M. (2012). The influence of heel height on patellofemoral joint kinetics during walking. Gait \& Posture, 36, 271-275.

LaBella, C. (2004). Patellofemoral pain syndrome: evaluation and treatment. Primary Care, 31, 977-1003.

Magnusson, S.P., Langberg, H., \& Kjaer, M. (2010). The pathogenesis of tendinopathy: balancing the response to loading. Nature Reviews Rheumatology, 6, 262-268.

Powers, C.M., Lilley, J.C., \& Lee, T.Q. (1998). The effects of axial and multiplane loading of the extensor mechanism on the patellofemoral joint. Clinical Biomechanics, 13, 616-624.

Self, B.P., \& Paine, D. (2001). Ankle biomechanics during four landing techniques. Medicine 85 Science in Sport $\&$ Exercise, 33, 1338-1344.

Selvanetti, A., Cipolla, M., \& Puddu, G. (1997). Overuse tendon injuries: basic science and classification. Operative Techniques in Sports Medicine, 5, 110-117.

Shorten, M.R. (1993). The energetics of running and running shoes. Journal of Biomechanics, 26, 41-51.

Sinclair, J., Bottoms, L., Taylor, K. \& Greenhalgh, A (2010). Tibial shock measured during the fencing lunge: the influence of footwear. Sports Biomechanics, 9, 65-71.

Sinclair, J., Taylor, P.J., Greenhalgh, A., Edmundson, C.J., Brooks, D., \& Hobbs, S.J. (2012). The test-retest reliability of anatomical co-ordinate axes definition for the quantification of lower extremity kinematics during running. Journal of Human Kinetics, 35, 15-25.

Sinclair, J., \& Bottoms, L. (2013). Gender differences in the kinetics and lower extremity kinematics of the fencing lunge. International Journal of Performance Analysis in Sport, 13, 440-451.

Sinclair, J., Greenhalgh, A., Brooks, D., Edmundson, C.J. \& Hobbs, S.J. (2013a). The influence of barefoot and barefoot-inspired footwear on the kinetics and kinematics of running in comparison to conventional running shoes. Footwear Science, 5, 45-53.

Sinclair, J., Taylor, P.J., \& Hobbs, S.J. (2013b). Alpha level adjustments for multiple dependent variable analyses and their applicability-a review. International Journal of Sports Science \& Engineering, 7, 17-20.

Sinclair, J. (2014). Effects of barefoot and barefoot inspired footwear on knee and ankle loading during running. Clinical Biomechanics, 29, 395-399.

Sinclair, J., \& Bottoms, L. (2014). Gender differences in the Achilles tendon load during the fencing lunge. Baltic Journal of Health and Physical Activity, 6, 199-204.

Sinclair, J., Taylor, P.J., Currigan, G., \& Hobbs, S.J. (2014a). The test-retest reliability of three different hip joint centre location techniques. Movement 83 Sport Sciences, 83, $31-39$. 
1 Sinclair, J., Isherwood, J., \& Taylor, P.J. (2014b). Effects of foot orthoses on Achilles tendon load in recreational runners. Clinical Biomechanics, 29, 956-958.

Sinclair, J., \& Bottoms, L. (2015). Gender differences in patellofemoral load during the epee fencing lunge. Research in Sports Medicine, 23, 51-58.

Sinclair, J., Atkins, S., Taylor, P.J, \& Vincent, H. (2015a). Effects of conventional and minimalist footwear on patellofemoral and Achilles tendon kinetics during netball specific movements. Comparative Exercise Physiology, (In press).

Sinclair, J., Chockalingam, N., Naemi, R., \& Vincent, H. (2015b). The effects of sport-specific and minimalist footwear on the kinetics and kinematics of three netballspecific movements. Footwear Science, 7, 31-36.

Sinclair, J., Hobbs, S. J., \& Selfe, J. (2015c). The Influence of Minimalist Footwear on Knee and Ankle Load during Depth Jumping. Research in Sports Medicine, (In press).
Sinclair, J., Toth, J., \& Hobbs, S.J. (2015d). The influence of energy return and minimalist footwear on the kinetics and kinematics of depth jumping in relation to conventional trainers. Kinesiology, 47, 11-18.

Sinclair, J., Hebron, J., \& Taylor, P.J. (2015e). The Test-retest Reliability of Knee Joint Center Location Techniques. Journal of Applied Biomechanics, 31, 117-121.

Sinclair, J., Taylor, P.J., \& Atkins, S. (2015f). Effects of new military footwear on knee loading during running Footwear Science, (In press).

Van Eijden, T.M., Kouwenhoven, E., Verburg, J., \& Weijs, W.A. (1986). A mathematical model of the patellofemoral joint. Journal of Biomechanics, 19, 219-229.

Vuckovic, G., \& James, N. (2010). The distance covered by winning and losing players in elite squash matches. Kinesiologia Slovenica, 16, 44-50. 